\title{
INTEGRATED SCIENCES FOR HERITAGE REUSE: INTERDISCIPLINARY STUDIES ON THE PIARIST COLLEGE OF SAN GIUSEPPE IN CAGLIARI (ITALY)
}

\author{
D. R. FIORINO, V. BAGNOLO, S.M. GRILLO, S. NONNE \& M. SCHIRRU \\ Department of Civil Environmental Engineering and Architecture (DICAAR), University of Cagliari, Italy
}

\begin{abstract}
This study report illustrates the first results of a large-scale interdisciplinary research, currently in progress, carried out on the remarkable Piarist College of San Giuseppe Calasanzio in Cagliari (Sardinia, Italy). More specifically, the article focuses on the definition of criteria, standards and tools for the selection and management of the technological and scientific know-how in the knowledge plan, contributions that are becoming increasingly common in the restoration project. The former idea of the scientific programme was to consider the site as a research and teaching laboratory of Architectural conservation. However, the interdisciplinary nature of the studies involved and the exceptional opportunity provided by the site to think more deeply on the complex relationships between the different branches of sciences in the field of Restoration and to define efficient protocols for the planning and management of single multidisciplinary contribution to the preservation and reuse design project were immediately apparent.

The report therefore seeks to put forward some cause for reflection and, at the same time, describes the methodology developed for the specific case study, based on the stratigraphic analysis applied to the urban and architectural scale. In fact, the specific character of San Giuseppe College is that of being a wide architecture included in the densely stratified old town. The entire knowledge plan has been conceived as a multilayered stratified knowledge and indirect and on-site analysis required a multidisciplinary team composed, till now, by experts in the field of architectural restoration, history of architecture, survey and geomaterials, but further contributions have been planned in terms of urban analysis, structural efficiency, services and technical performance of manufactures. The tool of the 'Raumbuch', specifically adapted to the purpose, seems to be the best way of managing the spreading knowledge and of cross-checking the flowing information.

Keywords: chronology of structures, constructive techniques, diagnostic, material, Piarist architecture, stratigraphy, Raumbuch, reuse, Survey
\end{abstract}

\section{INTRODUCTION}

The study here presented is the first result of a multidisciplinary research project, still in progress, developed by the Laboratory of Restoration of the University of Cagliari, School of Architecture, in cooperation with a panel of academic experts in survey and drawing, history of architecture, urbanism, geomaterials, physics, structures and diagnostics ${ }^{1}$.

The overall objective of this research programme is to contribute at the definition of a methodology for the respectful restoration and sustainable reuse of multilayered historical buildings included in stratified old towns. Starting from the awareness that the deep knowledge of every single artefact that composes a monumental site is a crucial step for the development of a sustainable rehabilitation project [1-4], the multidisciplinary research team has already set up an efficient protocol of investigation based on the indirect and on-site analysis tested on selected typologies of historic buildings [5, 6]. However, the planning, schedule and management of the multidisciplinary scientific contribution has always appeared as a critical juncture in the research, even for small artefacts. This complexity, as it is well known, seriously increases considering wide architectural complexes in stratified urban areas descending from the merging of different kind of pre-existent historic buildings. 

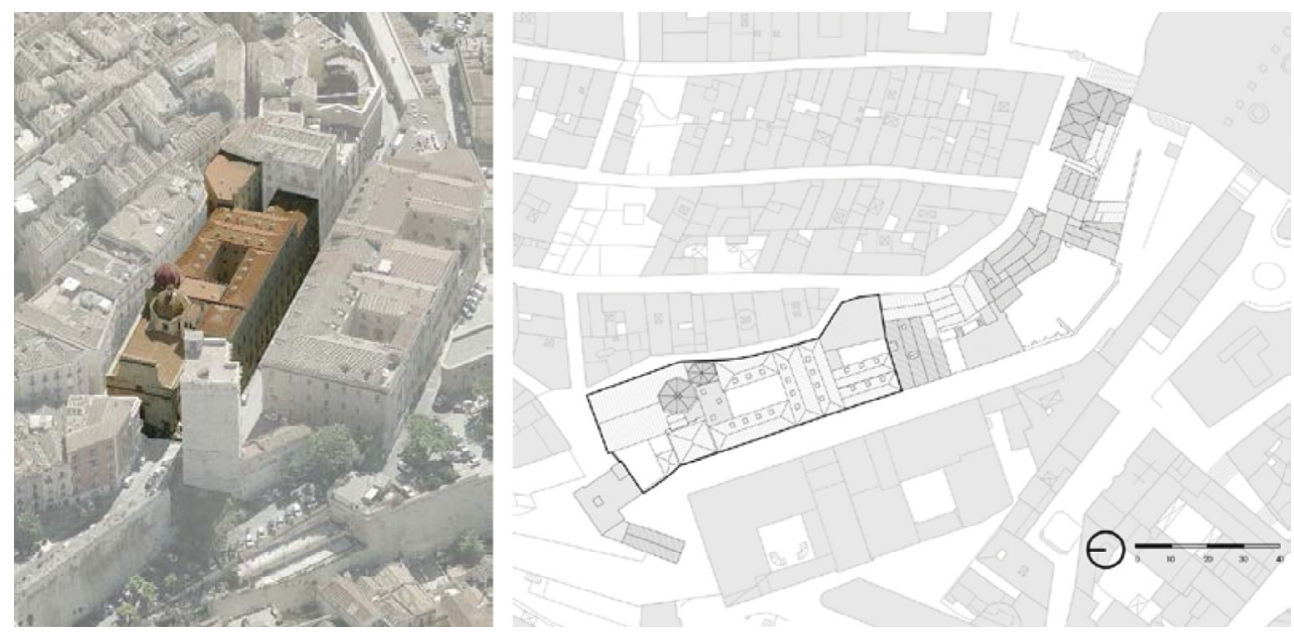

Figure 1: The Piarist College of San Giuseppe in the historic quarter of Cagliari, called 'Castello'. The image shows the strategic location of the building, hinged on the nearby defence Elephant Tower, interrupting the framework of the medieval urban fabric.

This is what happens in the College of San Giuseppe Calasanzio in Cagliari, built at the half of the 17th century transforming a densely stratified urban area (Fig. 1) that includes the first walled perimeter of the city, built in the 13th century. The result of this long historic process is a multilayered set of buildings with a wide range of construction techniques due to a very lengthy period (13th-19th centuries). The investigation on the religious site started in 2012 as a pilot research and teaching case study inside the Laboratory of Restoration. However, the interdisciplinary nature of the studies involved and the exceptional opportunity provided by the site to think more deeply on the complex relationships between the different branches of sciences in the field of restoration and to define efficient protocols for the planning and the management of the single multidisciplinary contribution inside a coherent overview of the multifaceted preservation and reuse design project were immediately evident.

\section{MULTILEVEL INVESTIGATION METHODOLOGY ON STRATIFIED SITES}

Currently the state of the art on interdisciplinary studies on Sardinian monuments, unlike what has been acquired for decades in other Italian regions, is quite poor, due to the lack of systematic studies, often with dramatic consequences for the conservation of historic buildings, owing to the absence of recognition of historical and documentary values. On the contrary, it's very common to coming across fully documented restoration projects where there isn't any relationship between preliminary investigations and restoration choices. This is a very dangerous way of conceiving the ethics of Restoration, considering the deep alteration potentially introduced by the modern system, services and structural works. This worrying situation is the direct consequence of at least three main causes. The first one is that, due to the Italian laws for public works, diagnostics are quite often possible only during the worksite and not in the planning phase. Luckily, this well-known problem is avoided increasing the funds available for the project itself. 
The second reason is the lack of ongoing cooperation between researchers and practitioners involved in multidisciplinary investigations. The final outcome in this condition is a multilayered analysis without any connection among different levels of information. The key objective of the work is, instead, a stratified and cross-linked knowledge. Actually, brainstorming meetings and co-working attitude are very useful measures for a successful and constructive technical dialogue. But, most of all, what is required is an effective tool able to stimulate and support the comparison and the cross-check of the heterogeneous information collected.

The third aspect is strictly related to the previous and refers to the interpretation of the investigation results and identification of historic and artistic values.

This is traditionally the end of the knowledge plan and the beginning of the planning stage. What usually happens is that a lack of connection between the two phases of the project causes the undermining of the investigative efforts; we actually are seeing the demolition of constructive elements both not correctly evaluated or, as opposite, defined as culturally interesting, which in a lot of ways is even worse.

At this point the question is: how is it possible that even accurate knowledge plans give rise to such underwhelming restoration project? The answer is to be found in a specific step of the decisional process the moment in which the designer decides the fate of every single element described in the investigation phase. It has already become widely accepted that the restoration act is a cultural, personal and even creative intellectual product [7,8]. Nevertheless, it is also true that what throws the design choices into crisis is the failure to recognize and manage different levels of historic and artistic values with operational consequence on conservation modalities. The critical synthesis that makes Restoration an ethic act [9] should be supported by methodological and procedural tools to support action plans and to shift the main project goals from 'what to preserve' to 'how to preserve'.

In order to face and solve this problem, the present research proposes an investigation process based on stratigraphic approach, multilayered analysis and the use of the tool of the 'Raumbuch' $[10,11]$, as a synthesis matrix, here further properly transformed into a multilevel value assessment sheet.

\subsection{The multilayered analysis}

The protocol of investigation is based on a multilayered analysis, considered as a series of thematic investigations, following a generally held methodological process. This process consists of two main phases, carried out in parallel, one indirect and the other direct.

The indirect phase is based (1) on the consultation of bibliographic sources and archival documents; (2) on the transcription of documents considered more significant for the reconstruction of the history of the site, and in particular the instructions of the designers, bill of quantities and contracts; (3) on the analysis of historical city maps and iconography useful for the reconstruction of long-term urban transformations; (4) on the analysis of project designs, views and historical pictures for the definition of the limits ante quem and post quem when absolute dates are unavailable; (5) on the elaboration of chronological schemes of synthesis, both in plan and in elevation which facilitate the understanding of the various phases of construction; (6) on the comparison of the relative chronology with archival information in order to date and define every single element of the building.

The direct phase includes: (1) the architectural survey or the updating and revising of the available ones. This step also considers innovative technologies such as three-dimensional models and photomap of architectural surfaces; (2) the survey of construction techniques and 
vaults system; (3) the thematic mapping of materials and relative mineralogical-petrographic analysis of samples; (4) the assessment of the state of conservation of materials and structures; (5) the analysis of the urban and architectural interfaces related to urban and architectural stratigraphy; and (6) specific panel of diagnostics for the investigation of further aspects (thermography, ground-penetrating radar, etc.).

\subsection{The stratigraphic approach and the multidisciplinary hubs}

The original scientific contribution to the generally held methodological process is to consider the multilayered analysis as a single step of the wider investigation process, not the final one. The innovative point is the stratigraphic approach to the investigation phase, applied to the urban and the architectural scale. In fact the already well-codified stratigraphic and archaeometric analysis has amply demonstrated the efficiency of the interdisciplinary comparison that comes from different field of sciences, making stratigraphy as a sort of hub of knowledge, intended as a knowledge belonging from a dense contribution of several sciences, specifically oriented to the definition of chronologies. If we consider that every stratigraphic analysis ends with the chronological interpretation within the Harris matrix, it's a natural thought that a multilayered analysis also requires an interpretation tool, usually not included in the process, leaving the information unconnected and less effective for the restoration process. But then, which are the other multidisciplinary hubs? Beyond chronology, the methodology considers

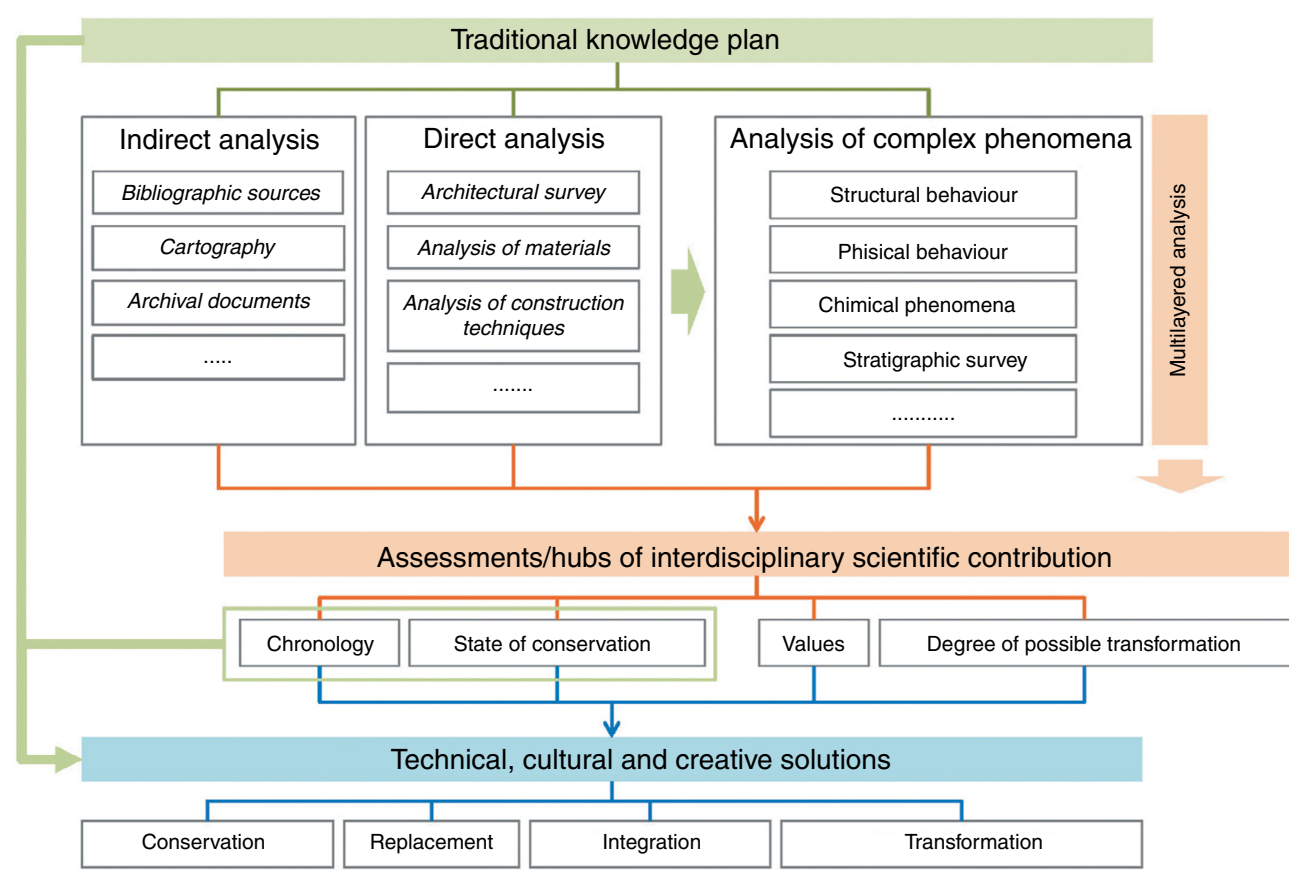

Figure 2: The flow chart illustrates the role of the 'hub criteria' in the traditional restoration process, acting as an intermediary element for the cross-check of the multidisciplinary contribution and the management of the additional parameters (value and degree of possible transformation). 
the following additional hubs: the state of conservation, the identification of values and the degree of possible transformation. A conceptual framework is in Fig. 2.

\subsection{Piloting and assessment tools}

The cross-check of the information in the knowledge hubs cannot be random. The most suitable way of managing this kind of information is the use of a specific assessment form, properly designed for the application of this methodology, but deeply inspired by the 'Raumbuch' model. In detail, the tool consists in a sequence of data-sheet arranged as a hierarchical system. The conceptual framework is in Fig. 3. Every room of each building is described through a form where every single element is analysed and assessed according to some parameters and indicators. Each of them can change into a codified range of values. The room form also contains a session dedicated to the planning and management of the knowledge. The conceptual framework is in Fig. 4. It is a matrix where every investigation (from the archival survey to technical instrumental diagnostics) is described and related to the element or the problem that requires the analysis (general aim); and the main result and the state of the survey (planned, in progress, completed, that needs further investigations). This report is very useful for the monitoring of the knowledge plan, in order to avoid waste of time and money in unnecessary scientific insights.

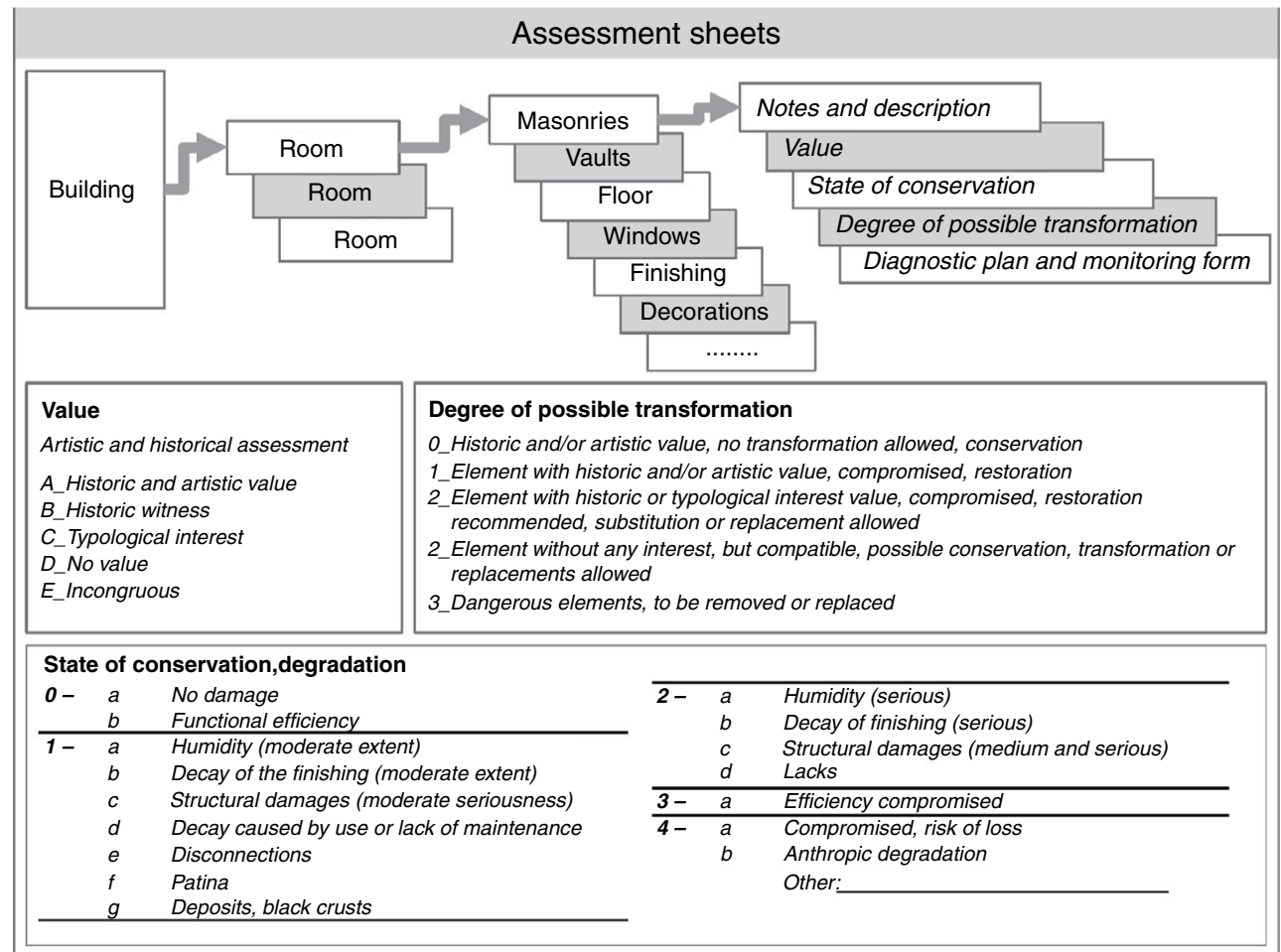

Scale of values for parametes and indicators used in the assessment matrix

Figure 3: The flow chart illustrates the data-sheet framework and the scale adopted for the interdisciplinary assessments (value, state of conservation, degree of eligible transformation). 


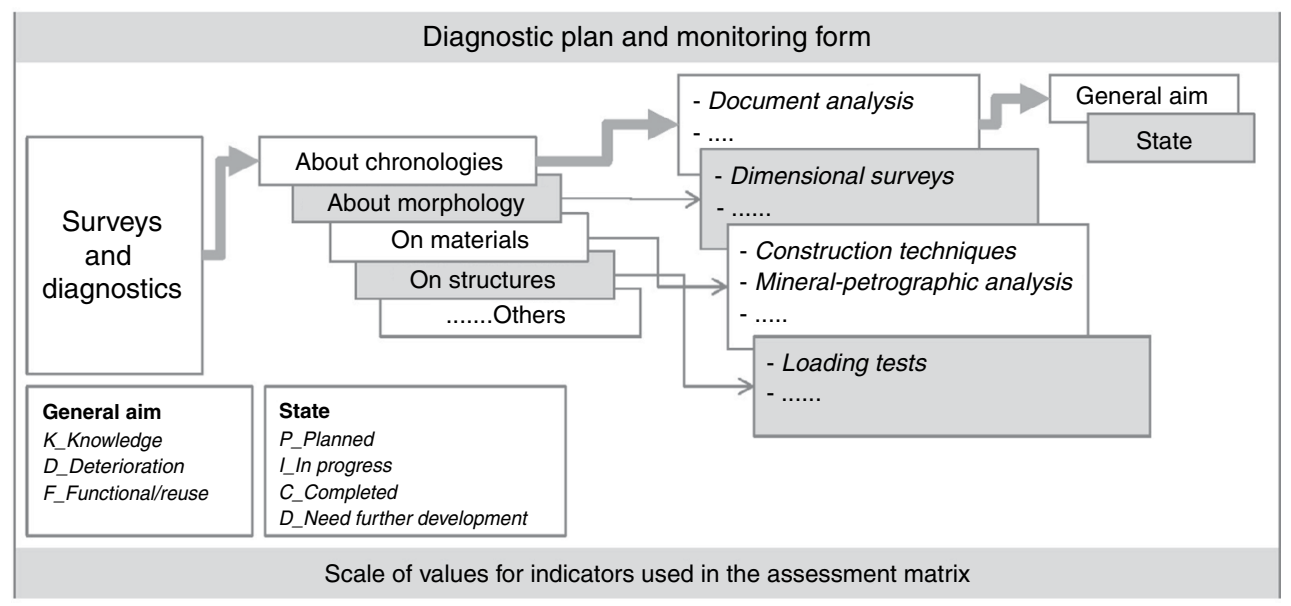

Figure 4: The flow chart illustrates the framework of data-sheet designed to support the planning, monitoring and management interactions of thematic investigations.

\section{THE MULTILAYARED ANALYSIS ON SAN GIUSEPPE COLLEGE}

\subsection{The application of the multilevel methodology on the case study}

The illustrated methodological process has been conceived as a cultural guidance for the project of rehabilitation and reuse as well as an efficient tool for the monitoring of the restoration worksite. The strong point of the research is that the method is easily applicable to different typologies of architecture. Some interesting results have already been achieved on civil and military architetures $[12,13]$. However, the most interesting test has been carried out on the wide religious complex of San Giuseppe Calasanzio in Cagliari.

The college with the church was built in 17th-18th centuries incorporating medieval urban walls and some private mansions, merged together into a modern convent.

The analysis started with the consultation of bibliographic and archival sources, published and unpublished, kept in the State Archives of Cagliari, Turin and Barcelona, in the archive of the local office for Cultural Heritage Protection and in the Sardinian Archives of Contemporary Architecture (MEM) in Cagliari. All the documents significant for the reconstruction of the history of the site have been transcribed. Regarding contemporary sources, it's important to specify that relevant information came from the analysis of the restoration project carried out in the second half of 20th century with important suggestions for the assessment of the values and degrees of freedom in terms of possible transformation.

At the same time, an extended rigorous three-dimensional survey, intended as a fundamental tool for the comprehension of the morphology of the site, has been carried out. The investigation has moved forward with the architectural survey, the mapping of materials, and the analysis of the construction techniques with particular regard to some selected masonries.

On the basis of the results, an accurate stratigraphic analysis has been started, both at the architectural and urban scale. Theoretically, documentary sources are essential for chronological aims to define absolute dating. However, with reference to Sardinian monuments, the documentary sources are few and scattered - or even missed - in several archives in Sardinia, 
Italy and Spain, due to historical phases of the region. In addition, if we consider mansions, it is not easy to associate the historical information to each specific building so that very often the only way to compose the intricate puzzle is the cross-check of the collected heterogeneous data (such as owners, boundaries, toponymy) [6].

For these reasons, in the study of the College of San Giuseppe, the information deriving from traditional archival researches needed to be integrated with the critical reinterpretation of historical maps and urban plan. A useful activity was also the accurate analysis of old images belonging to public and private collections, such as postcards, urban views from international travellers as well as drawings produced during previous restoration projects carried out from the second half of 19th century to the late 20th century.

Furthermore, in order to support the interpretation of the chronological sequence and to investigate structures and general state of conservation, the research required some notdestructive diagnostics such as the mineralogical-petrographic analysis of samples by optical microscopy and X-ray diffraction.

The collected multidisciplinary data traced a first hypothesis about the chronological sequence of constructions and transformations of the college and its site. Furthermore, respecting the different degree of transformation, first ideas for adaptive reuse were developed reconsidering the old Piarist residence and religious school the reuse as a university centre dedicated to the School of Architecture [14].

\subsection{The history of the site through the analysis of the archival sources}

The Piarist Fathers arrive in Cagliari in the fourth decade of the 17th century. Their Order is one of the last to settle in the capital of Sardinia, thanks to the direct engagement of the City Hall and government authorities. Like all ecclesiastical settlements, the newly born college benefits of generous legacies, without which it would be impossible to implement a programme of integration in the social life of the city. Developing an effective settlement strategy is one of the priorities for the Fathers: the architectural and urban components of the project play a considerable role for an Order voted to education and training of elites.

The prestige recognized to the St. José de Calasanz's followers is witnessed by the interference of state and municipal authorities in the foundation of their college in Cagliari [15]. In the post-Tridentine cultural climate, the flourishing of ecclesiastical residences offers interesting opportunities to those who seek tools of personal and family promotion. To finance the building of a religious complex, a church, a presbytery, a chapel, reserving patronages and burial rights, it is one of the highest expressions of success to citizen's eyes. In the Early Modern Age, the ride to these privileges is one of the most tried and tested channels of production of art works.

The story of the College San Giuseppe Calasanzio is not an exception to this tradition. As mentioned before, the intervention of public authorities promotes the arrival of the Piarist Fathers in Cagliari, but their project would not be possible without the intervention of a private supporter. The Ordà family, devoted since decades to the notarial practice, is committed to support the religious in their hard architectural and urban programme. The wealthy bourgeoisies give the Piarist a building complex along the carrer of Oriphany, now via San Giuseppe, near the Elephant Tower. They are mostly private residences - the first nucleus of the religious heritage in the capital of Sardinia [16].

Even in this case, the contacts with the civil authorities are recurrent, being the area characterized by multiple functions. The residences arisen along the street coexist with activities, 
pertinences and military servitudes; behind them, they rise the walls and medieval towers between the urban Elephant and Eagle Gates. In truth, the defence system is gradually losing its vocation; the Balice bulwark, built in the middle of the 16th century, has extended the boundaries of the castle, subtracting from the ancient fortifications the role of barrier along the western edge of the district.

As usual in the early stages of an ecclesiastical community, the first overall settlement differs, often quite substantially, from its final form. Those who observe the size and structure of the Piarist College in Cagliari today will not make it hard to imagine the complex shape of the institute where religious architectural, residential and coenobitic functions coexist [17]. The design and construction of these spaces are realized step by step, through the progressive acquisition of private buildings subtracted to the historical buildings of the castle.

The early 17 th century manuscripts written by the Piarist Fathers testify the construction of a primitive settlement, with the church, of which no trace remains $[15,18]$. Previous archival sources confirm the presence, in the same site, of private residences belonging to the Ordà family: probably, the buildings coincide with the aforementioned real estate donation to the religious [16].

In course of time, there came donations from other benefactors and the Royal State Property, aimed to extend the first college. In 1678, when the architectural works start, the state officials oblige Piarist Fathers to stretch a line between the Elephant Tower and the Brondo's properties, located in the area which, a century later, will host the Royal Theatre [19].

The church of San Giuseppe Calasanzio adopts a plan model of Lombard-Ligurian derivation, developed within the fold of post-Tridentine aesthetic culture, whose disclosure in Sardinia is favoured by the settlements of the Society of Jesus [20, 21]. Three pairs of symmetrical chapels face the single nave covered by a barrel vault and communicating with the presbytery, on which dominates an octagonal pavilion. On either side of the apse, there are two identical rooms destined to the sacristy and archives. Throughout the 17th century, the described model is very successful in Sardinia, as evidenced by the large series of examples, in Cagliari, Sassari and other places in the region [22]. At the moment, the designer of the church and the college remains unknown. However, we can assume that workers were the same as in the nearby cathedral where, since 1669 operated a large team of artists and builders from Liguria.

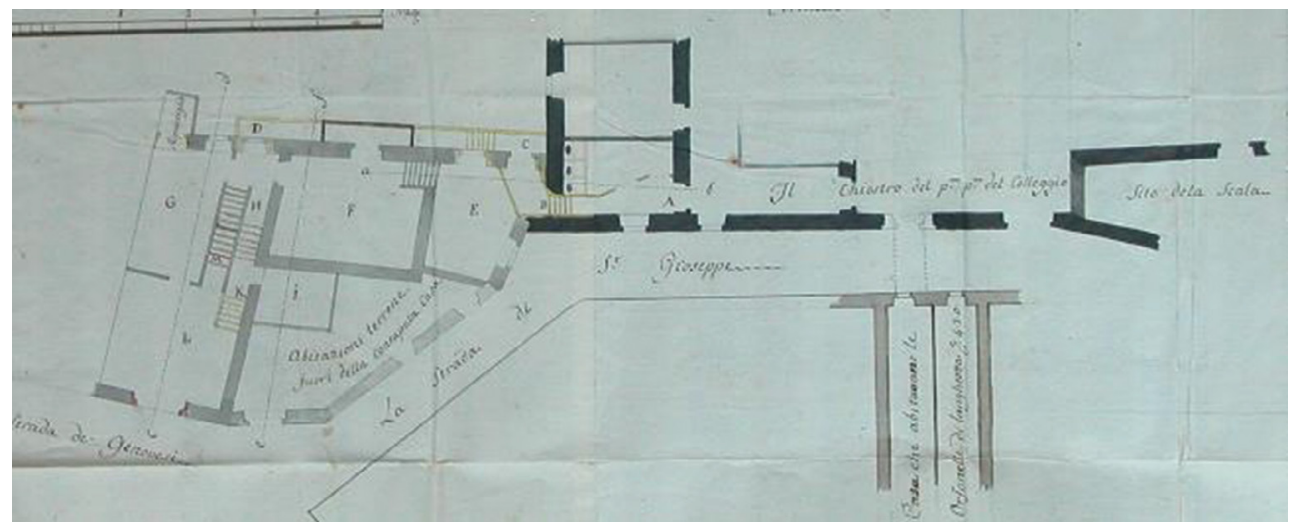

Figure 5: Project for the reuse of the Piarist College as university classrooms (maybe by an engineer Saverio Belgrano di Famolasco), 1765 (A.S.To, Paesi, Sardegna, Materie Politiche, Categoria 10, Mazzo 4, n. 16). 
The building of the Piarist College continues till the 18th century and beyond when the last works in the church and schools get finished. Among the most interesting innovations we include the staircase inside the institute, covered by an octagonal pavilion built by the designer Antonio Ferdiani, in 1758 [23] (Fig. 5). In 1777, the sculptor Giovanni Battista Franco, a native of the Intelvi Valley, designs and makes the sumptuous marble furnishings in the church $[24,25]$.

The 19th century was no less eventful for the Piarist Fathers residence. In the first decade of the century, the painter Francesco Massa decorates the ceiling of the sacristy. They are, however, the subversion laws $(1855,1866)$ to inaugurate a new era for the former college. Intended to be used as Civil Court and primary school, the building is being restored because of the new functions, under the direction of engineers Enrico Melis [26] and Enrico Besson [27].

\subsection{Architectural survey and morphology}

The Piarist College of San Giuseppe in Cagliari is a complex system arising from the combination of individual episodes that must be read and interpreted both in the urban and architectural scale [28]. The urban scale is crucial as the monument has incorporated a section of the urban fortification system between two important medieval towers, the Torre dell'Elefante and Torre del Leone. This important issue has affected the entire architectural survey process, which was also aimed at identifying the permanence of some sections of urban fortifications. The architectural surveying is part of a wider research that also considers the relations established between some buildings of the Castello district and the different stages of fortifications.

In the architectural survey process, some important preliminary steps were fundamental, first of all the purpose of the survey project and the choice of the methodology. It refers to a proper integration between different survey methods and instrumental equipment, aiming to create a graphic representation model addressed at summarizing the historical-critical cognitive process. The different thematic models are in fact derived from an integrated survey campaign using traditional instruments of direct detection in conjunction with surveying with total station and new low-cost technologies for architectural photogrammetry [29]. The graphical representation includes a set of multiple functions and the concept of drawing as an imitation of reality appears exceeded: the different levels of realism which we can refer are only one of the aspects that we need to address. The graphic representation doesn't want to achieve realism or mimesis, but, by making comprehensible complex systems, it should stimulate us to reflect about the analogies with tangible and intangible meanings.

The college buildings are organized around two courtyards: the cloister and a second inner courtyard closed inside the city block in the late 18th century. The two areas are located both on the line of the medieval walls of the Castello district. The main buildings of the college are ranged around the quadrilateral cloister surrounded by covered walkways and attached to the church located on the north side. The cloister lies at the main entrance level on via San Giuseppe, a narrow road inside the Castello district. The cloister consists of round open arcades, today closed by floor-to-ceiling windows. Although today the connections have been closed, the church and the sacristy were linked to the college. Originally with sloping wooden roofs, today the college is covered with hipped and flat roofs in brick reinforced concrete slab, realized under the project of restructuring actions taken by engineer Romano Antico during the late sixties of the 19th century. The college comprises various parts belonging to different building units, multilayered in different construction phases. The superimposed masses 


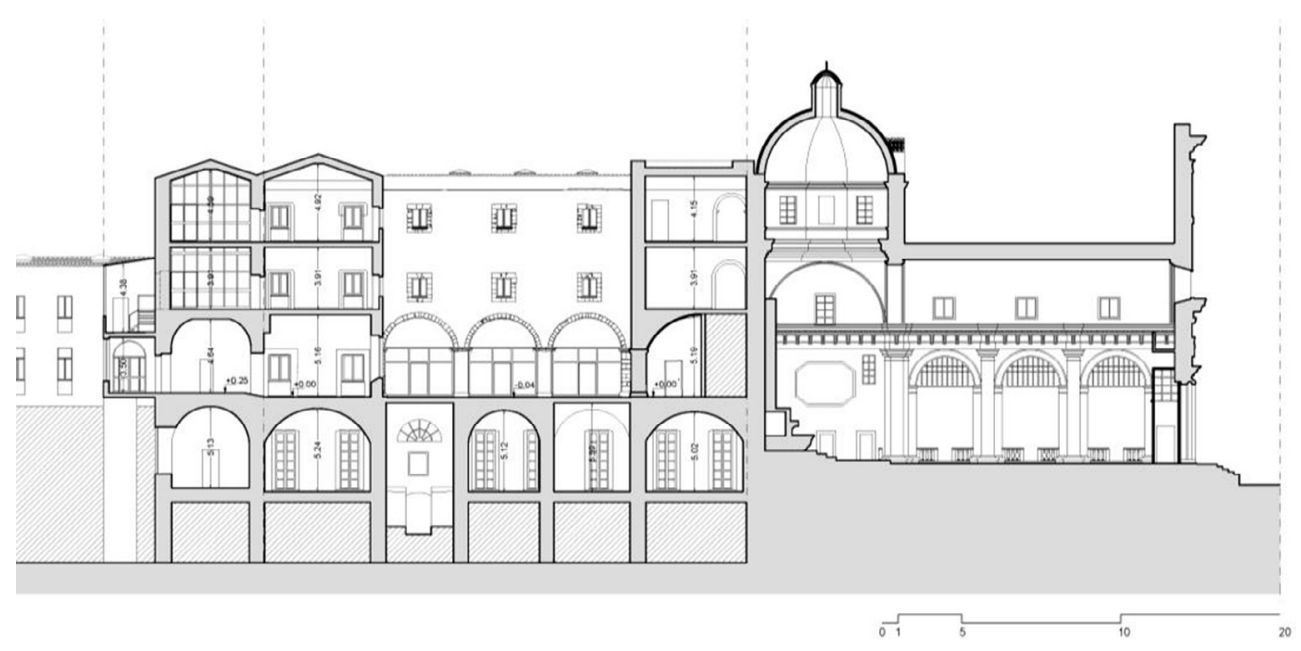

Figure 6: Section of the monument.

build up a complex whole on five storeys (Fig. 6). The building is located on an area that has an average drop of about $14 \mathrm{~m}$ : entering the building from via San Giuseppe, you reach the cloister which runs horizontally at a height of $14 \mathrm{~m}$ above via Università street level.

As a whole, the building is on five levels, with two basement levels, ground floor and two upper storeys for those accessing from via San Giuseppe. On the via Università, the college has a facade with five floors above ground. The complex occupies an area of $1,500 \mathrm{~m}^{2}$, including the college and the church. Besides the original spaces, the complex also includes the last two levels of an adjacent building that overlooks via Università. Within its imposing frame are different rooms and halls, covered by horizontal slabs, barrel vaults, sometimes with lunettes, sail vaults, cross vaults and pavilion. Stone masonries rise up to five floors ( $24 \mathrm{~m}$ on via Università, and $15 \mathrm{~m}$ on the via San Giuseppe) and are topped by a clay tile roof except for a part of the building with a flat roof. In the lower floors we can see the presence of important sections of the medieval walls [30,31].

The lower level, overlooking the via Università, today hosts some art studios and cultural associations offices. Its plan is characterized by the succession of load-bearing masonry walls erected with a medium pitch between 5 and $5.4 \mathrm{~m}$. The bearing walls are arranged orthogonally relative to the orientation of the facade on via Università, establishing a succession of barrel vaulted rooms supporting the trend of the stony slope of Castello hill.

The first results of the survey show the medieval fortification line for a stretch coincides with the inner perimeter of the block on via San Giuseppe, while another section of the city walls coincides with the southern front that faces the most recent. Carrying out the survey operations, special care has been taken to highlight and express the different degrees of knowledge of the architectural characteristics, in order that not only they may be preserved and protected, but also to make possible their rehabilitation by improving the accessibility of knowledge.

In the traditional architectural survey, measuring operations and graphical representation are delineated as separate and distinct moments. In the survey of the College of San Giuseppe, the acquisition and representation of data occur in the same time as joint actions of the process of knowledge. The digital graphic model of the college can refer to different 
purposes and lead to different outcomes, being able to express different levels of reading and interpretation of the site. As well as separately, the data must be considered in their mutual relationships, experiencing the different possible interaction between the architectural and urban dimensions. The construction of the digital model has pursued the two-fold requirement to have a description that not only produces life-like images that simulate the reality, but also provides a graphic restitution which reviews and presents the outcomes of the different thematic analyses [32].

\subsection{Constructive techniques and materials}

The study of the constructive techniques mainly focused on the dating of the masonries. The builders mainly used limestone stone, locally named pietra forte and pietra cantone [33]. Structures have a wide chronology, as a consequence of the known practice, especially in 15th-18th centuries, of reusing - or recycling - pre-existences during the construction of new buildings inside urban perimeters [34].

The basements give testimony of an earlier urban configuration, not completely erased by the construction of the religious buildings, but reused as useful warehouse or simply strong groundwork. The advanced state of decay, which affects many of the constructive surfaces in the basements, allowed stratigraphic investigations and a deep study of materials and techniques for this area of the college. Foundations lay directly on the outcropping bench of 'pietra forte'.

The oldest masonry samples refer to the Pisan city walls (13th century). This masonry, still preserved in the south courtyard, is characterized by regular courses of large ashlars. Other structures related to the military paths are also evident in the basements. We can easily identify remains of arches and vaulted aisles, later adapted to warehouses of modest private houses placed against the city walls (15th-18th centuries) (Fig. 7). In fact, in 16th century, as a common practice in the urban transformations, new buildings were based on existing solid urban walls. This was a warranty for safe construction, but also a way for saving time and money.

With the arrival of the Fathers and the building of the Piarists college, the construction techniques change, switching from using regular masonry of pietra forte to 'a sacco' masonry with cantonals and shoulders of the openings in square blocks of well-worked pietra cantone. This technique can easily be seen in the first floor on the via Università and in upper floors of the college. In particular, it is interesting to notice the frequent presence of wedges of slate in the joints of the squared blocks. This is a recurring and well-dated technique, used in Cagliari in the 17th century in several contemporary worksites (San Giacomo, Santa Croce). Upper floors still show complex signs of transformations, additions and demolitions, as well as restoration evidences.

In the current state of the research, the chronological analysis of the basements has produced first interesting chronological hypothesis, by means of a reasoned sampling of masonries with mineral-petrographic investigation on mortars and plasters. Masonries were studied according to the stratigraphic methodology $[2,35,36]$, through an archaeological relief and the faithful representation of the different layers in order to discover the continuity and discontinuity of architectural structures, their interfaces and, consequently, their chronology.

Geometrical features such as the thickness, direction and verticality of the walls, the change of height in the level of horizontal structures and the mutual relationship between walls suggest important stratigraphic relationships, both architectural and urban. Considering that the 
monument lies on a wide urban area, the survey should consider the entire city district around the architectural complex. For this reason, architectural stratigraphy will be further developed as an urban stratigraphy strictly connecting the two levels of this thematic analysis [37].

Finally, cross-checking heterogeneous data derived from the multidisciplinary analysis, a first chronological sequence has been proposed, even if more analyses need to be carried out to confirm this first hypothesis. For example, the plaster protection used to cope with the weakness of the local limestone (pietra cantone) makes the investigation more complex and suggests additional diagnostics, such as an extensive thermography. Under the urban point of view, dated masonries could represent stratigraphic chronological witness, also being useful for dating other less documented buildings of the city.
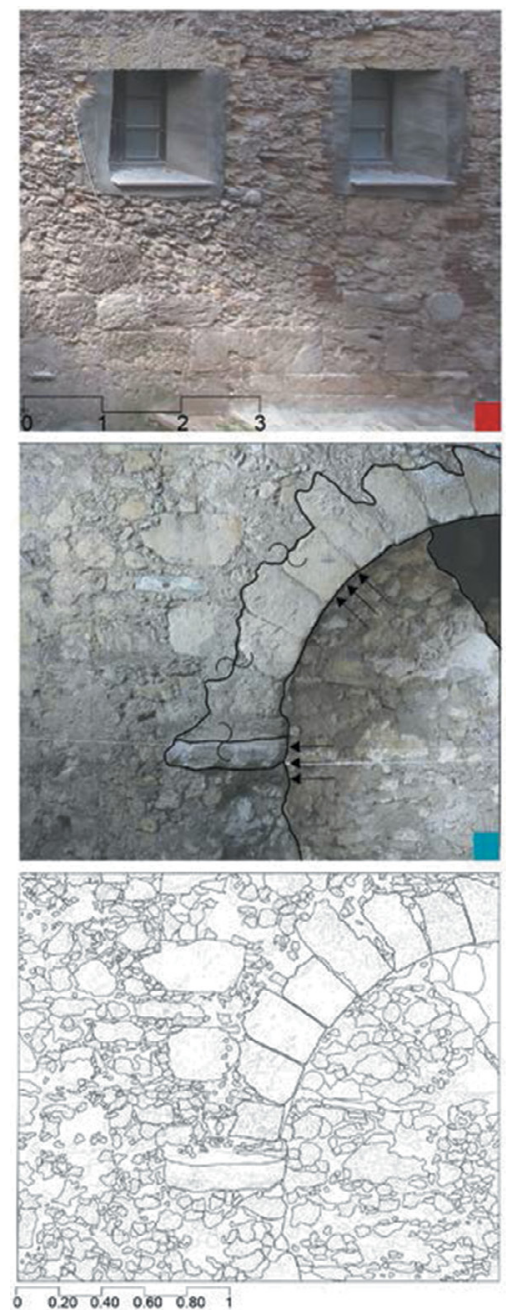
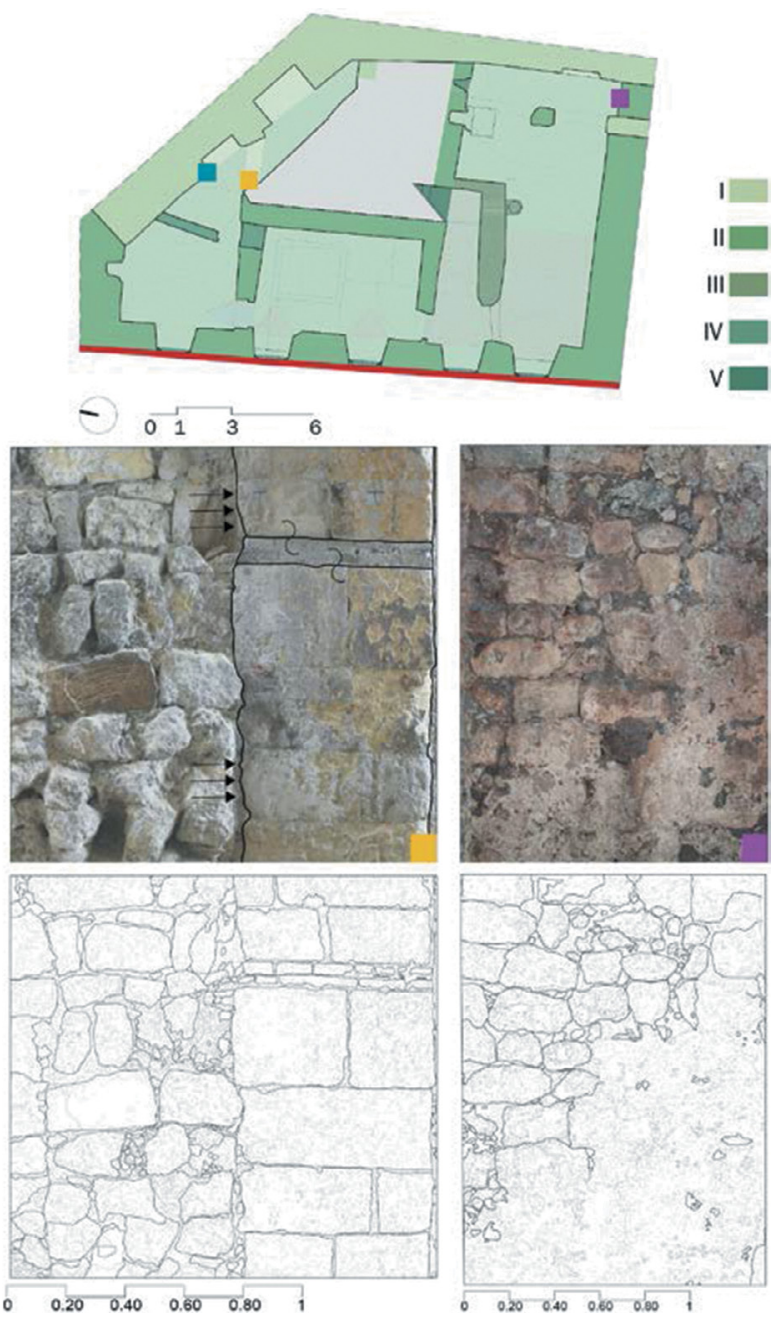

Figure 7: Relative chronology (phases I-V) of masonries samples in the convent basements. Structures refer to the ancient military walls and buildings later included in private houses. In particular, the red sample is a portion of the Pisan urban perimeter. 


\subsection{Structural aspects (DRF)}

The architectural complex generally shows good structural efficiency. This is probably a direct consequence of the several restoration works carried out in the second half of the 20th century. These works considerably transformed the structural scheme of the architecture, by the introduction of concrete framework, horizontal structures and roofs in brick reinforced concrete slab. The structural mixture makes San Giuseppe College a very interesting case study in terms of research on ancient-new interfaces.

The only critic point is actually the interfaces between the college and the sacristy, where a kinematic motion is clearly in progress. This structural movement is causing relevant passing cracks on the pavilion that covers the sacristy, making at risk the conservation of the paintings.

The causes have to be found in the relative movement between two buildings (the sacristy and the college) related to different constructive phases. Further specific structural will be launched very soon, due to the urgency of the local situation.

\subsection{Documentary tools}

Great effort has gone into documenting the studied elements using the data-sheet first described in the general methodology. This data framework could be further improved and is ongoing to be developed as a BIM (Building Information Modelling). This implementation will be particularly useful in the assessment phase, in order to clearly point out those parts of the monument that are still authentic and those referable to the several transformation and restoration works carried out on the buildings. Moreover, collating historical and technical information in a three-dimensional model, the study will be able to supply a detailed risk map where every single element is marked with a degree of vulnerability and transformability. This is the first step towards a sustainable reuse. Contemporarily, other different tools were tested: the informative systems developed by the Italian Ministry for Cultural Heritage SIGEC/web and SICAR/web [38].

\section{COMPARATIVE STUDIES AND ASSESSMENT HUBS: THE ANALYSIS OF THE SACRISTY}

\subsection{Site-specific research and the investigation plan}

While the research has started on the entire architectural complex, the first complete application of the described methodology was made on the sacristy of the church. It is a very interesting vaulted room which still retains its original decorations and furnishings. Particular mention should also be made for pavilion painting with a fake dome perspective, more interesting for the subject than for the technical ability of the artist, maybe Francesco Mossa.

The protocol followed the steps outlined in the framework of Fig. 2 and the multilayered analysis was successfully managed gathering and cross-checking the thematic information into the already introduced assessment sheet of Fig. 3. The investigations started with the analysis of the bibliographic and archival sources, the dimensional and architectural relief, the analysis of materials, and the assessment of the state of conservation. The stratigraphy analysis was mainly conducted on mortars and plasters, starting from the bedding interstice of the masonry to the painted surface. Several interdisciplinary scientific contributions were required to solve specific interpretative doubts and many others are planned, following a 
precise diagnostic plan, described in the detailed monitoring form of Fig. 4 that allowed the ongoing overview of the investigations. It's a direct consequence that the greater the accuracy of the process, the more the quality of the restoration project will be.

\subsection{Analysis and ND diagnostics}

The survey of the vaulted room started in March 2015 [39]. The first step was the updating and revising of the previous architectural survey by the direct relief of the plan and of the photomap of the inner fronts, including the pavilion (Fig. 8).

This geometrical base allowed the mapping of materials and the analysis of degradation. Main degradations of plastered surfaces are salt efflorescence, lacks, deposits and layers of recent plasters incompatible with the older one.

The decorated vault also shows deep cracks, large areas of separation between masonry and layers of plasters, and wide lacks in the decorated surface. This situation is the result of an active movement of structures. The consequent cracks in the slatted surface follow a parabolic pattern.

The first element to investigate was the structure itself in order to verify if the pavilion was of a stone vault or a suspended ceiling. With this aim, the staff of ND diagnostics of the department joint the research team and supported the investigation with a ground-penetrating radar scan of the floor of the library, which vertically corresponds with the sacristy's vault.

The analysis (Fig. 9) confirmed the following constructive stratigraphy: the vault was built with blocks of 'pietra cantone' with a thickness of approximately $40 \mathrm{~cm}$; above it there were a layer of filler material, probably incoherent, and then the floor screeds and the marble pavement. The entire structure is approximately $60-70 \mathrm{~cm}$ thick. Moreover, the overlapping between the cracks pattern and the tomography highlights the correspondences of the information coming from the two levels of investigation. The cross-check of the data provides useful details on the extent, depth and thickness of the cracks.

\subsection{Sample and materials}

The analysis on plasters and mortars had two-fold aims: on the one hand, the definition of relative and absolute chronologies and, on the other hand, the knowledge of the constructive
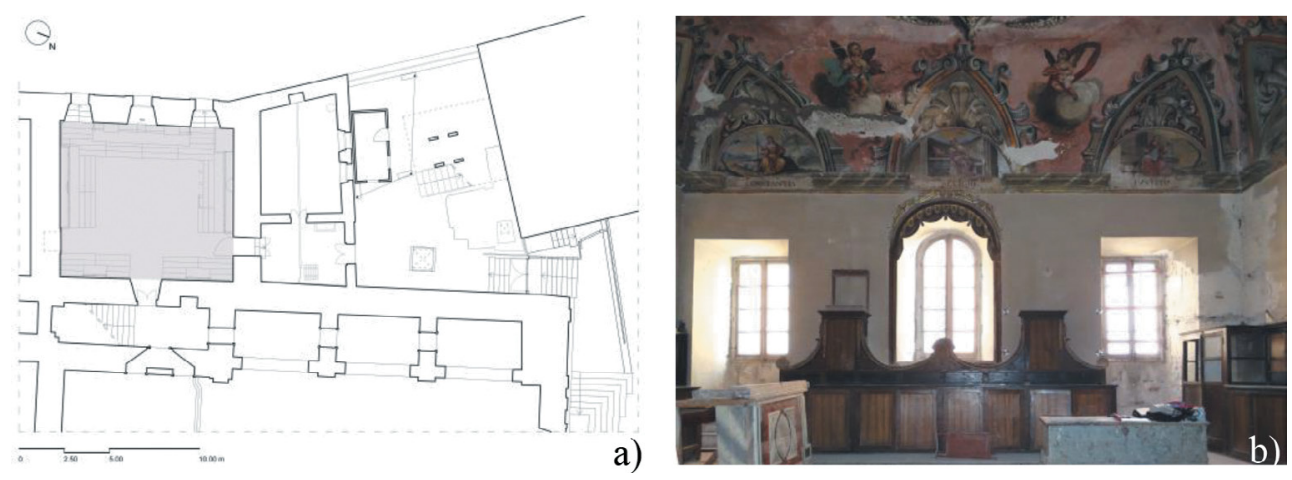

Figure 8: The sacristy of San Giuseppe church: (a) plan of the room (in grey) as a detail of the general map of the religious site; (b) a view of the vaulted room with the wooden sacred furniture. 


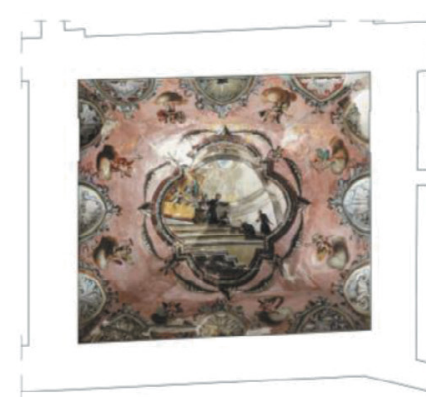

a)

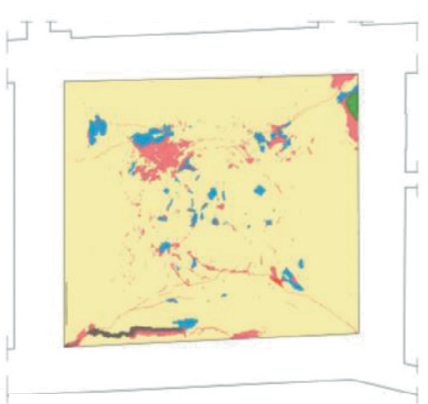

b)

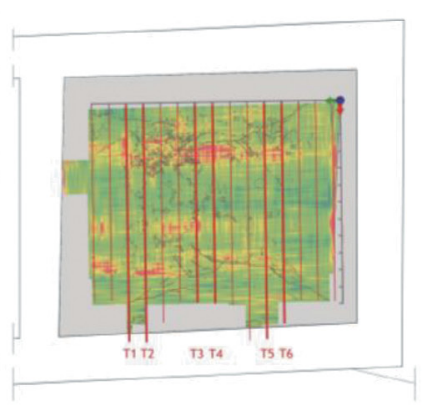

c)

Figure 9: Diagnostics on the sacristy of San Giuseppe church: (a) photomap of the painted vault; (b) map of the cracks interesting the pavilion: cracks and lacks in red, surfaces with low cohesion in blue, concrete integrations in grey, no decay in light yellow; (c) in red lines the main grid of the ground-penetrating radar investigation carried out on the library floor and the horizontal tomography (depth $-0.56 \mathrm{~m}$ ) compared to the relief of cracks.

technique for the deep understanding of the deterioration processes and the identification of compatible new restoration materials. The protocol began with the analysis of the stratigraphy starting from the bedding interstice of the masonry to the surface (Figs 10 and 11). By the methodological support of the stratigraphic analysis it has been possible to identify two typologies of plasters, with the related finishing. A mineralogical and petrographic characterization was carried out by Polarized Light Microscopy observations to identify the composition and texture of mortars and plasters. The mortar (M04) has a fine-grained aggregate with similar fractions size, mainly consisting of mono-crystalline quartz, feldspar and fragments of echinoid spine, and inorganic carbonate. The binder is calcic lime with micrite structure and lumps, resulting from late hydration and carbonation, showing similar but still distinguishable characteristics of the surrounding binder [40, 41].

The plaster (I04) has light grey colour, a light red smooth finishing and a good cohesion. This plaster shows the same characteristics of the mortar. The plaster (I01) lies on the plaster (I04). It has light grey colour and low degree of cohesion. It is characterized by an aggregate similar to the sample I04, but with thicker crystals. The binder is calcic lime with micrite structure; it shows abundant presence of lumps that are often cracked, pores with irregular shape and rims that are occasionally encased by calcite crystals. The binder/aggregate ratio is relatively fat [42]. The sample of the painted plaster (IE2) belonging to the pavilion is one of the fragments collapsed from a deep crack because of a water infiltration from the roof. The sample shows the same characteristics of the I01 with a very thin layer of the painting.

Under the petrographic microscope the samples of mortars and plasters show the same composition. This can be easily explained by the fact that the sands of the aggregate always came from the local beaches, because sample from different chronology can show the same composition. The only difference is the shape and size of minerals. The mineral-petrographic analysis of the stratigraphy has permitted an understanding of the different typologies of mortars, in relation to the building phases. The comparative study of the samples, also referred to other case studies in the city, leads to confirm, for the mortar M04 and the plaster I04, the same chronology of the construction of the complex as we know from the archival sources, that is, the second half of the 17th century. 

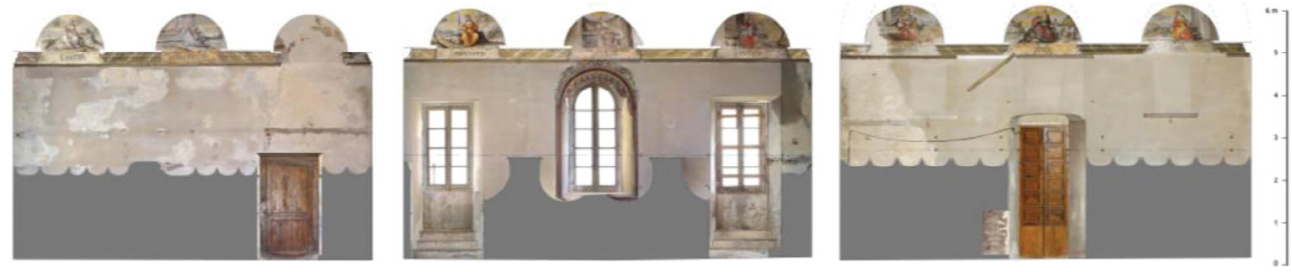

Figure 10: Photomap for the thematic relief of the inner surfaces.
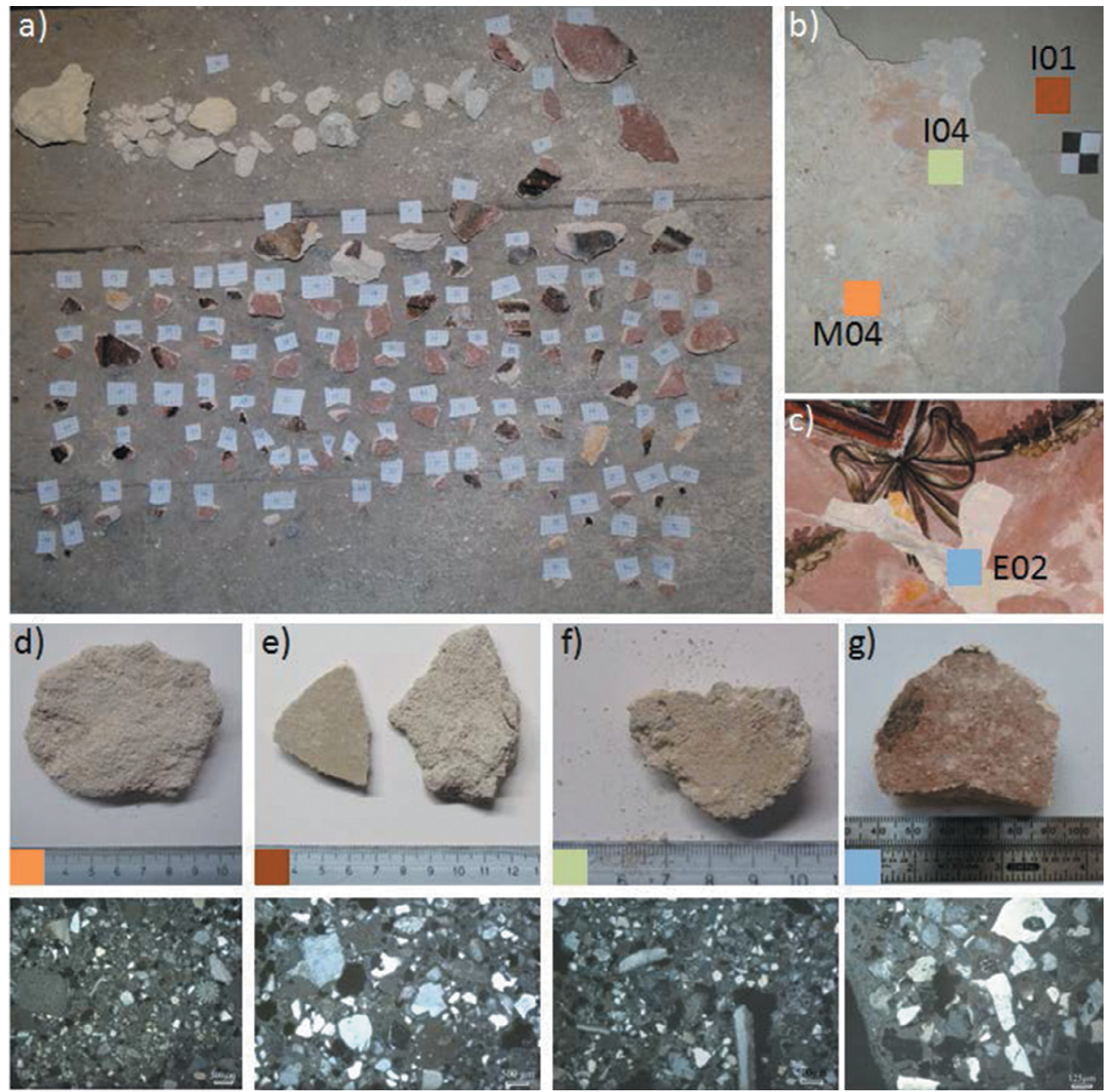

Figure 11: Macro and micro analysis of the samples of the sacristy: (a) first catalogue of the fragments from the decorated plaster collapsed from a deep crack; $(b, c)$ localization of samples; the sequence: sampling phase and micro photos in thin section by optical microscopy; (d) mortar M04; (e) plaster I01; (f) plaster I04; (g) plaster E02. 
The second layer is due to a subsequent drafting dated around the early 19th century, in correspondence with the tempera decoration of the pavilion. This chronology is confirmed by the correspondence between the microscopic analysis of samples (IE2) and (I01).

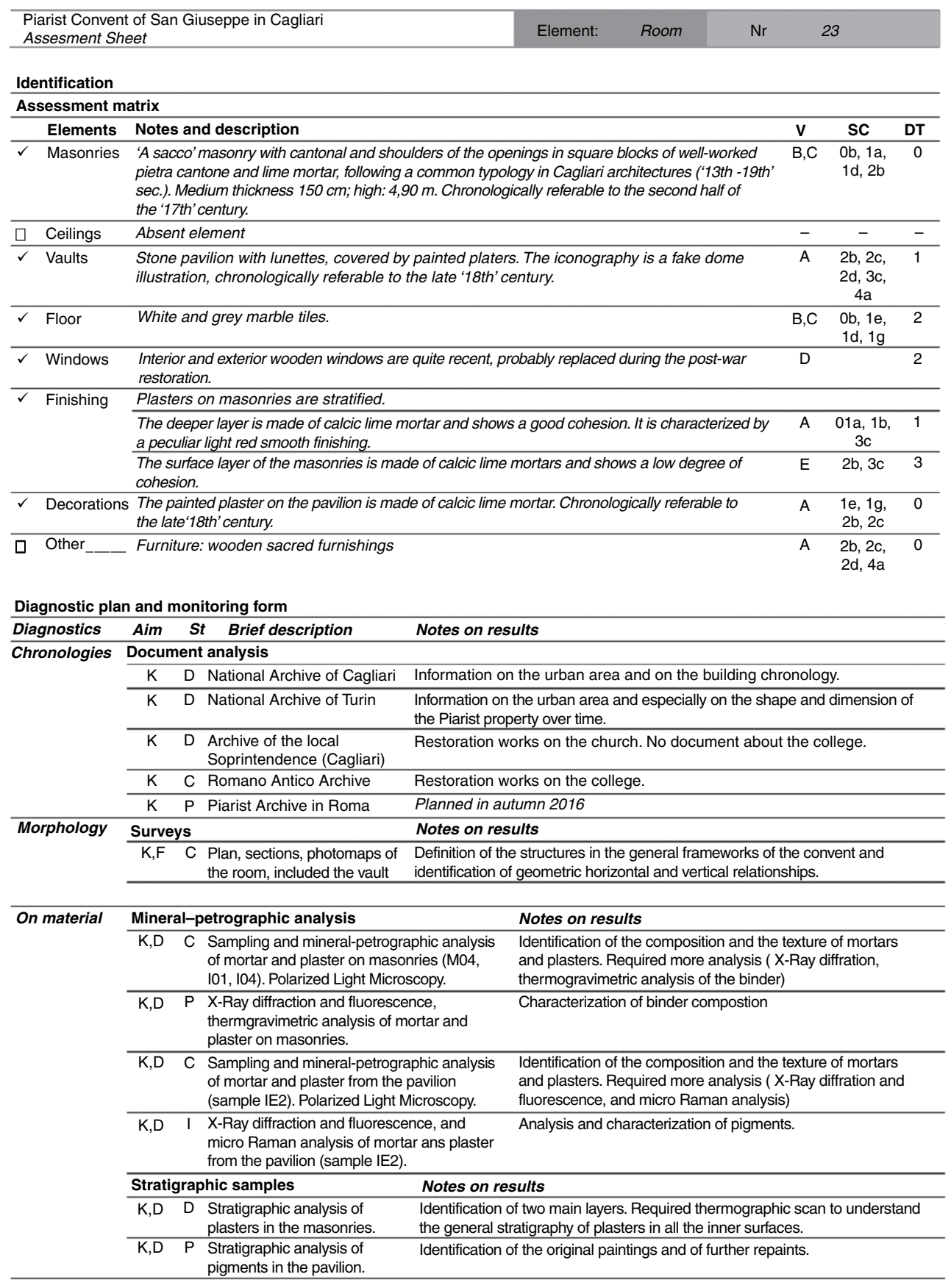

Figure 12: Assessment sheets for the sacristy. Legend of parameters in Figs 3 and 4. 


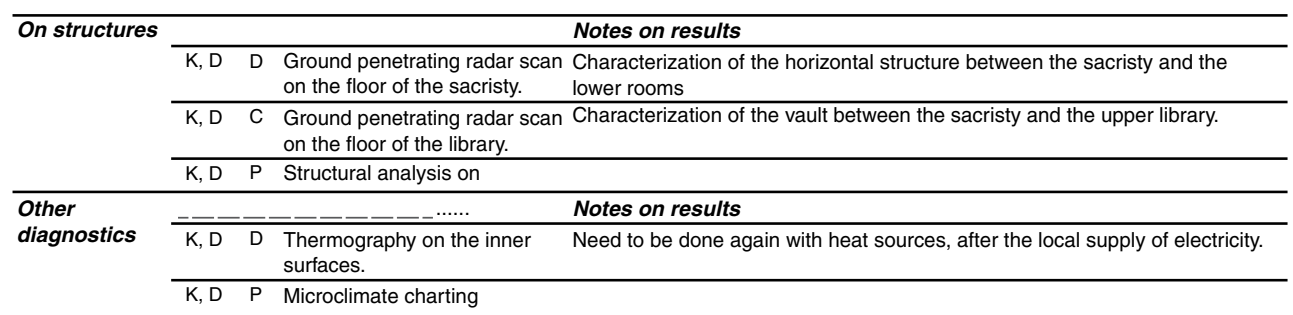

Figure 13: Further elements of the assessment sheet. Legend of parameters in Figs 3 and 4.

The definition of material benchmarks for masonries, mortars and plasters is relevant for the future chronological study of the entire architectural complex. In fact, in the next phases of the research new samples will be appropriately compared to these for an even more detailed understanding of the monument.

\subsection{The assessment hubs}

During the investigation phase, every planned analysis has been coordinated within a monitoring plan in order. Built up upon the expertise of the tool of the 'Raumbuch', a new assessment matrix has been developed. The data-sheet confirmed its helpfulness in the cross-check of the data and in the management of diagnostics. In fact, it enables a very detailed check and assessment of every single element of the building, for a culturally inspired restoration project. Figs 12 and 13 give example of the assessment tools used for the analysis of the sacristy. Even if the test has been successful, the definition of the grid is still in progress in order to improve parameters and scales of evaluation.

\section{CONCLUSIONS}

The detailed studies carried out on the College of San Giuseppe Calasanzio in Cagliari confirmed the efficiency of the innovative methodology developed for the management of multidisciplinary analysis on stratified buildings.

Focusing on the specific case study, further investigations are required to complete an indepth multidisciplinary layer analysis. To give some examples, even if in a non-exhaustive list, stratigraphic research needs to be implemented from the architectural to the urban scale; topographic and geometrical survey needs to be extended to the entire monumental site; the study of the masonries and constructive techniques need more samples and reliefs. Moreover, structural investigation is quite urgent, as illustrated for the sacristy where the crack pattern needs further check and monitoring of damages as soon as possible, because of the high risk in structure stability of the vault. However, the surveys and diagnostics carried out on the monumental site are already a valuable input for testing the assessment process of the cultural heritage. In fact, the first results were promising in order to draw a suitable and well-focused conservation project. The resulting analysis and interpretation outcome provided by the innovative tools for the understanding of material and immaterial values will provide effective guidelines for a careful and respectful conservation and adaptive re-use project.

\section{NOTES}

${ }^{1}$ The introduction and the conclusions were written by all the authors; All the paragraphs in Chapter 2 (2.1, 2.2 and 2.3), paragraph 3.1, 3.5, 3.6, 4.1 and 4.4 by D.R. Fiorino; paragraph 3.3 by V. Bagnolo; paragraphs 3.4 and 4.3 by D.R. Fiorino and S.M. Grillo; paragraph 4.2 by 
S. Nonne; paragraph 3.2 by M. Schirru. The iconographic apparatus was coordinated by D.R. Fiorino and S.M. Grillo; Figs 2, 3 and 4 were carried out by D.R. Fiorino; section in Fig. 6 and plans and samples in Fig. 7 by M. Barrui, A. Murgia, S. Tavera, and drawings of samples in Fig. 7 by A. Murgia, supervised by V. Bagnolo and D.R. Fiorino; plan and pictures in Figs 8, 9 and 10 by S. Nonne, supervised by D.R. Fiorino and G. Ranieri (Applied Geophysics Laboratory); pictures (a), (b), (c) and (g) in Fig. 11 by S. Nonne; pictures of sample (d), (e) and (f) and the macro and micro analysis of materials in Fig. 11 by S.M. Grillo (LabMAST Laboratory - unit for material characterization); the assessment sheet in Figs 12 and 13 was developed by D.R. Fiorino and S.M. Grillo.

\section{REFERENCES}

[1] Docci, M. (ed.), Gli strumenti di conoscenza per il progetto di restauro, Gangemi: Roma, 2003.

[2] Doglioni, F., Stratigrafia e restauro. Tra conoscenza e conservazione dell'architettura, Lint Editoriale: Trieste, 2002.

[3] Fiorani, D., Restauro e tecnologie in architettura, Carocci: Roma, 2009.

[4] Musso, S.F., Tecniche di restauro, Utet: Torino, 2013.

[5] Fiorino, D.R., Giannattasio C. \& Grillo S.M., Fortificazioni e cronologie: protocolli conoscitivi per la conservazione. Verso un atlante dei sistemi difensivi della Sardegna, eds D.R. Fiorino \& M. Pintus, Giannini: Napoli, pp. 129-172, 2015.

[6] Fiorino, D.R., Giannattasio, C., Grillo, S.M., Pintus, V., Porcu, M. \& Schirru, M., Knowledge and dating for preservation of historical and cultural significance of the building: the case study of the medieval Castello quarter in Cagliari (17th-19th centuries). Proceedings of the 2nd International Conference on Preservation, Maintenance and Rehabilitation of Historical Buildings and Structures, R. Amoêda, S. Lira \& C. Pinheiro (eds), Green Lines Institute: Porto, pp. 523-534, 2015.

[7] Zanardi, P., Il restauro. Giovanni Urbani e Cesare Brandi, due teorie a confronto, Skirà: Milano, 2010.

[8] Carbonara, G., Alcuni temi di restauro per il nuovo secolo, Trattato di Restauro Architettonico Primo Aggiornamento, eds G. Carbonara, Utet: Torino, pp. 1-50, 2007.

[9] Bellini, A., Conservation and use of our architectural heritage: An ethical problem, Territorio, n. 64, Franco Angeli: Milano, pp. 9-17, 2013.

[10] Petzet, M. \& Mader, G., Praktische Denkmalpflege, Kohlhammer: Monaco, 1993.

[11] Valli, L., Vecchie abitudini e nuovi strumenti. Diacronie, 10 (2), 2012. DOI: 10.4000/ diacronie. 2860.

[12] Fiorino, D.R., Scientific advice for the architectural, stratigraphic survey and analysis of materials of the Caserma Cascino in Cagliari, available at http://www.mit.gov.it/mit/ site.php? $\mathrm{p}=\mathrm{cm} \& \mathrm{o}=\mathrm{vd} \& \mathrm{id}=4078,2015$ (Accessed 21 January 2017).

[13] Santoni, V., Riconversione del bastione di San Filippo a Cagliari e valorizzazione del paesaggio storico urbano. Studi per un Distretto dell'Arte (DAC), Master degree thesis in Architecture, University of Cagliari, Supervisor prof. D.R. Fiorino, academic year 2015/2016.

[14] Barrui, M., Murgia, A. \& Tavera, S., Misura, Analisi, Restauro. Studi interdisciplinari per il riuso del complesso monumentale di San Giuseppe a Cagliari, Master Degree Thesis in Architecture, University of Cagliari, Supervisors Professors D.R. Fiorino, V. Bagnolo, G.B. Cocco, S.M. Grillo \& M. Schirru, academic year 2015/2016.

[15] Colli Vignarelli, F., Gli Scolopi in Sardegna, Gasperini: Cagliari, 1982. 
[16] DOC.A, Archivio di Stato di Cagliari, Ufficio dell'Insinuazione, Tappa di Cagliari, Atti Sciolti, notary Michelangelo Bonfant, vol. 70, s.c.

[17] Pintus, M., Il rilievo della chiesa di San Giuseppe a Cagliari. Arte e cultura del $600 e$ 700 in Sardegna, ed. T.K. Kirova, ESI: Napoli, p. 138, 1984.

[18] Spagnesi, G., L'architettura religiosa degli Scolopi e la Chiesa di San Giuseppe a Cagliari. Arte e cultura del 600 e 700 in Sardegna, ed. T.K. Kirova, ESI: Napoli, pp. 128-129, 1984.

[19] DOC. B Archivio de la Corona de Aragón (Barcellona), Consejo de Aragón , Legajos, Busta 158, doc. 3 February 1678.

[20] Repishti, P., Gli esordi di Pellegrino Tibaldi architetto. Domenico e Pellegrino Tibaldi Architettura e arte a Bologna nel secondo Cinquecento, eds Francesco Ceccarelli \& Deanna Lenzi, Marsilio: Venezia, 2011.

[21] Bonavita, A., Un inedito di Pellegrino Tibaldi: la chiesa di Sant'Agata Martesana, Annali di Architettura, XV , Centro Internazionale di Studi Andrea Palladio: Vicenza, 2003.

[22] Cadinu, M., Il rudere della chiesa di Santa Lucia alla Marina di Cagliari. Architettura, archeologia e storia dell' arte per il recupero di un luogo della città medievale, Archeoarte. Ricerca e Confronti, 1, 2010.

[23] DOC.C, Archivio di Stato di Cagliari, Ufficio dell'Insinuazione, Tappa di Cagliari, Atti Insinuati, December 1758, vol. 470, s.c.

[24] DOC.D, Archivio di Stato di Cagliari, Ufficio dell'Insinuazione, Tappa di Cagliari, Atti Insinuati, January 1777, vol. 918, cc. 904-906, notary Francesco Demontis.

[25] Schirru, M., Un artista intelvese nella Sardegna del XVIII e XIX secolo: lo scultore Giovanni Battista Franco. La Valle Intelvi, XII, Comunità Montana Lario Intelvese: San Fedele Intelvi (Co), 2008.

[26] Kirova, T.K., (ed.), Cagliari, quartieri storici. Castello, Pizzi: Cinisello Balsamo (Mi), 1985.

[27] DOC.E, Archivio di Stato di Cagliari, Prefettura, versamento 1920, serie I, busta 108/16.

[28] Bagnolo V. \& Pirinu A., The designs for the reuse of the fringe areas around the fortified walls of the Castello District in Cagliari. Architettura e Città, problemi di conservazione e valorizzazione, eds A.Marmori, L.Puccini, V.Scandellari \& S.Van Riel, Altralinea Edizioni: La Spezia, pp. 307-314, 2015.

[29] Bagnolo V., Ortofoto da scansione laser di quinte edilizie in contesti storici urbani, Sandhi editore: Ortacesus, 2010.

[30] Fiorino, D.R. \& Pirinu, A., Interdisciplinary contribution to the protection plan of the fortified old town of Cagliari (Italy). International Journal of Heritage Architecture, 1 (2), WIT Press: Southampton, pp. 163-174, 2017. DOI: 10.2495/HA-V1-N2-163-174.

[31] Pirinu, A., A Geographic Information System for the documentation of medieval and modern fortifications. The district of 'Castello' in Cagliari, eds C.Gambardella, Fabbrica della Conoscenza n. 56, 'Le Vie dei Mercanti. Heritage and Technology Mind Knowledge Experience', La scuola di Pitagora: Napoli, pp. 739-746, 2015.

[32] Bagnolo V., Disegno e rilievo in contesti archeologici: l'esperienza di Uthina (OudhnaTunisia), Sandhi editore: Ortacesus, pp. 9-30, 2010.

[33] Fiorino, D.R. \& Grillo, S.M., Coastal cities and cultural heritage: problems of conservation and management. The case of the ancient walled city of Cagliari (Sardinia, Italy). Coastal Cities and Their Sustainable Future, eds G.R. Rodriguez \& C.A. Brebbia, WIT Transactions on the Built Environment: Southampton, vol. 148, pp. 111-123, 2015. 
[34] Fiorino, D.R., Stratigraphic evidence in the ancient urban walls of Cagliari (SardiniaItaly). Defence Sites II. Heritage and Future, eds C. Brebbia, C. Clark, WIT Transactions on the Built Environment: Southampton, vol. 143, pp. 257-268, 2014.

[35] Brogiolo, G.P. \& Cagnana, A., Archeologia dell'architettura: metodi e interpretazioni, All'Insegna del Giglio: Firenze, 2012.

[36] Francovich, R. \& Parenti, R., Archeologia e restauro dei monumenti, All'Insegna del giglio: Firenze, 1998.

[37] Fiorino, D.R., La stratigrafia urbana. Proposte per Stampace. Idee per un piano di conservazione del quartiere storico cagliaritano, eds C. Giannattasio \& P. Scarpellini, Gangemi: Roma, pp. 69-74, 2009.

[38] Fiorino, D.R., Tools for monitoring and managing historical buildings: The innovative use of the SICaR/web system, Arkos, vol. 11-12, Editinera: Roma, pp. 13-29, 2015.

[39] Nonne, S., Belle arti negate: il caso della sacrestia della chiesa di San Giuseppe a Cagliari, Master Degree Thesis in Building Architecture, University of Cagliari, Supervisors Professors D. R. Fiorino, S. M. Grillo, G. Ranieri, M. Schirru \& dr. E. Pilia, academic year 2014/2015.

[40] Crisci, G.M., Franzini, M., Lezzerini, M., Mannoni, T. \& Riccardi M.P. Ancient mortars and their binder, Periodico di Mineralogia, Special Issue, 'A showcase of the Italian research in applied petrology', 73, Nuova Cultura ed: Roma, pp. 259-268, 2004.

[41] Hughes, J.J. \& Leslie, A.B., The petrography of lime inclusion of historic lime based mortars. Proceeding of 8th Euroseminar on Microscopy Applied to Building Materials, Annales geologiques des pays Helleniques, Department of Geology: Athens, pp. 359-364, 2001.

[42] Pecchioni, E., Fratini, F. \& Cantisani, E., Atlas of the ancient mortars in thin section under optical microscope, Nardini editore: Firenze, pp. 1-78, 2014. 